\title{
Metoclopramide decreases emesis but increases sedation in tramadol patient-controlled analgesia
}

\author{
[Le métoclopramide diminue les vomissements, mais augmente la sédation chez des \\ patients qui reçoivent une analgésie auto-contrôlée avec du tramadol]
}

Wei-Wu Pang MD, ${ }^{*}$ Hurng-Sheng Wu MD, $†$ Ching-Hsiung Lin MD, ${ }^{*}$ Da-Peng Chang MD, ${ }^{*}$ Min-Ho Huang MD

Purpose: To evaluate the clinical benefits and disadvantages of adding metoclopramide to tramadol for patient-controlled analgesia (PCA).

\begin{abstract}
Methods: Forty adult patients, undergoing elective arthroplasties, were recruited into this prospective, randomized, double-blind study. During general anesthesia all patients received $2.5 \mathrm{mg} \cdot \mathrm{kg}^{-1}$ of tramadol as a loading dose at the beginning of wound closure. In the postanesthesia care unit (PACU) patients were randomly allocated to receive PCA containing either $20 \mathrm{mg}$ tramadol $+1 \mathrm{mg}$ metoclopramide per millilitre $(n=20$, Group T+M) or tramadol $20 \mathrm{mg}$ per millilitre $(n=20$, Group T). The PCA setup was I mL/bolus with a lockout interval of five minutes. A blinded investigator assessed the vital signs, visual analogue scale, and severity of postoperative nausea and/or vomiting in the PACU. The PCA demand and delivery, overall satisfaction rate and adverse effects were recorded in the PACU and on postoperative days one and two.
\end{abstract}

Results: Nausea/vomiting scores were more severe $(1.7 \pm 1.0$ vs $0.2 \pm 0.5,2.3 \pm 1.2$ vs $0.6 \pm 0.6,1.9 \pm 0.9$ vs $0.2 \pm 0.5$, at 12 $\mathrm{hr}, 18 \mathrm{hr}, 24 \mathrm{hr}$, respectively, $P<0.05)$ and more frequent $(7 / 20 \mathrm{vs}$ $1 / 20,5 / 20$ vs $0 / 20$ for nausea and vomiting respectively, $P<0.05$ ) on postoperative day one in Group $T$ compared to Group $T+M$. However, the incidence of sedation was higher in Group $T+M(7 / 20$ vs $1 / 20, P<0.05)$.

Conclusions: The incidence and severity of nausea/vomiting decreased if metoclopramide was added to tramadol for PCA. An increased incidence of sedation was noticed with this drug combination.

Objectif: Évaluer les avantages et les inconvénients cliniques de l'ajout de métoclopramide au tramadol pour l'analgésie auto-contrôlée (AAC).

Méthode : Quarante adultes devant subir une arthroplastie non urgente ont participé à l'étude prospective, randomisée et à double insu. Pendant l'anesthésie générale, tous les patients ont reçu $2,5 \mathrm{mg} \cdot \mathrm{kg}^{-1}$ de tramadol comme dose d'attaque au début de la fermeture de la plaie. Une fois à la salle de réveil $(S D R)$, les patients ont été répartis de façon aléatoire et ont reçu une AAC contenant soit 20 mg de tramadol + 1 mg de métoclopramide par millilitre $(n=20$, Groupe $T+M)$, soit $20 \mathrm{mg}$ de tramadol par millilitre ( $n=20$, Groupe T). L'AAC comportait des bolus de $1 \mathrm{~mL}$ et des périodes réfractaires de cinq minutes. Un chercheur impartial a évalué les signes vitaux, les scores de l'échelle visuelle analogique et la sévérité des nausées et des vomissements postopératoires. La demande et la disponibilité d'AAC, le taux de satisfaction générale et les effets indésirables ont été notés à la salle de réveil et les premier et deuxième jours postopératoires.

Résultats : Les nausées et les vomissements ont été plus sévères ( 1,7 $\pm 1,0$ vs $0,2 \pm 0,5,2,3 \pm 1,2$ vs $0,6 \pm 0,6,1,9 \pm 0,9 v s$ 0,2 $\pm 0,5$, à $12 \mathrm{~h}, 18 \mathrm{~h}$ et $24 \mathrm{~h}$, respectivement, $P<0,05)$ et plus fréquents $(7 / 20$ vs $1 / 20,5 / 20$ vs $0 / 20$ pour les nausées et les vomissements, $P<0,05)$, du premier jour chez les patients du groupe $T$ comparé au groupe $T+M$. Cependant, l'incidence de la sédation a été plus élevée chez ceux du groupe $T+M(7 / 20$ vs I/20, $P<0,05)$.

Conclusion : L'incidence et la sévérité des nausées et des vomissements diminuent si du métoclopramide est ajouté au tramadol pour I'AAC. Une incidence accrue de sédation a été notée avec cette combinaison de médicaments.

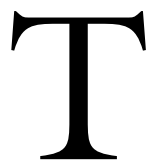

RAMADOL is a centrally acting analgesic with mostly non-opioid modes of action., ${ }^{1,2}$ In contrast to morphine, tramadol is reputed for its lesser respiratory depression, low potential for abuse, and acceptability for long term use. ${ }^{3}$ It is not a controlled substance in many countries. Unfortunately, because of its major side effects, namely

From the Departments of Anesthesia* and Surgery, $\dagger$ Show-Chwan Memorial Hospital Changhua, Taiwan, R.O.C.

Address correspondence to: Dr. Wei-Wu Pang, 7630 Pissarro Dr. Apt \# 108, Orlando, Florida 32819, USA. Phone: 407-351-8246; Fax: 407-351-8246; E-mail: sungfangrong@aol.com

This study was financially self-supported and carried out at the Department of Anesthesia, Show-Chwan Memorial Hospital, Changhua, Taiwan, R.O.C.

Accepted for publication May 27, 2002

Revision accepted September 5, 2002. 
nausea and vomiting, tramadol is not widely used for patient-controlled analgesia (PCA). ${ }^{4}$

Metoclopramide is a commonly used anti-emetic. Clinical studies have also reported a true analgesic effect from parenteral administration of this drug via a mechanism that remains unknown. ${ }^{5-8}$ By iv administration, the onset time and its plasma half-life are comparable with that of tramadol., ${ }^{4,-11}$

In this prospective randomized double-blind study, we evaluated the clinical benefits, disadvantages, especially the anti-emetic effect of adding metoclopramide to tramadol for PCA.

\section{Methods}

Following approval of the Hospital's Research Committee and after receiving patient informed consent, 40 adult patients ASA physical status I or II undergoing elective knee or hip arthroplasties were recruited into this prospective randomized doubleblind study. All patients were instructed on the use of the PCA and visual analogue score (VAS; $0=$ no pain, $10=$ the most excruciating pain) during the preoperative interview and again in the postanesthesia care unit (PACU). The exclusion criteria included: 1 ) difficulty in communication or inability to use PCA;2) allergy to the study drug(s);3) history of significant hepatic, cardiopulmonary or renal disease; 4) history of substance abuse; 5) obesity with body weight > $120 \%$ of the ideal body weight.

Anesthesia was induced with $4 \mathrm{mg} \cdot \mathrm{kg}^{-1}$ thiopental iv and $\mathrm{l} \mathrm{mg} \cdot \mathrm{kg}^{-1}$ succinylcholine iv. A $50 \%$ nitrous oxide $/ 50 \%$ oxygen + isoflurane mixture was used for anesthesia maintenance. Vecuronium was used as a muscle relaxant. No opioids, local anesthetics, antiemetics or non-steroidal anti-inflammatory drugs were administered $24 \mathrm{hr}$ before or during surgery. At the beginning of wound closure (about $40 \mathrm{~min}$ before the end of anesthesia), patients received a loading dose of $2.5 \mathrm{mg} \cdot \mathrm{kg}^{-1}$ of tramadol (Tramtor ${ }^{\circledR}$, Taiwan Patron Chemical \& Pharmaceutical Co. Taiwan) infused slowly. After the administration of tramadol, the isoflurane inspiratory concentration was decreased as needed.

After arrival in the PACU, patients were connected to a PCA pump (Pain Management Provider, Abbott Laboratories, North Chicago, USA). As soon as the patient complained of pain, the VAS was recorded and the PCA was started for pain control. Using a computerized randomization table, the patients were randomly allocated to one of two treatment groups, Group $\mathrm{T}+\mathrm{M}$ or Group T. Group $\mathrm{T}+\mathrm{M}(n=20)$ received a solution containing $20 \mathrm{mg}$ tramadol $+1 \mathrm{mg}$ metoclopramide per $1 \mathrm{~mL}$ normal saline. Group $\mathrm{T}(n=20)$ received a solution containing $20 \mathrm{mg}$ tramadol per 1
TABLE I Demographic data and type of operation performed

\begin{tabular}{lll}
\hline Group & $\begin{array}{l}T+M \\
n=20\end{array}$ & $\begin{array}{l}T \\
n=20\end{array}$ \\
\hline Age (yr) & $69 \pm 16$ & $71 \pm 12$ \\
Sex (male:female) & $8: 12$ & $10: 10$ \\
Weight (kg) & $59 \pm 12$ & $57 \pm 16$ \\
Height $(\mathrm{cm})$ & $161 \pm 9$ & $158 \pm 8$ \\
Physical status (I:II) & $4: 16$ & $3: 17$ \\
Duration of surgery (min) & $105 \pm 34$ & $98 \pm 37$ \\
Duration of anesthesia (min) & $133 \pm 21$ & $140 \pm 17$ \\
& & \\
Total hip replacement & 4 & 6 \\
Total knee replacement & 16 & 14 \\
\hline
\end{tabular}

Data are mean \pm standard deviation. No statistically significant differences between the two groups.

$\mathrm{mL}$ normal saline. The PCA bolus was $\mathrm{l} \mathrm{mL}$ and the lockout interval was five minutes. The study drug(s) were prepared by pharmacists and installed nurses who were not involved in the study. Patients were instructed to use the PCA to maintain a VAS $\leq 3$. Nurses were allowed to assist with PCA use at the patients' request. The onset time, vital signs (heart rate, blood pressure, oxyhemoglobin saturation), VAS, shivering, sedation, postoperative nausea and/or vomiting (PONV), and other side effects were assessed and recorded by two investigators (a senior anesthesia resident and the author himself), blinded to patient grouping. Onset time was defined as the period from administration of a PCA bolus to the patient's report of improvement. The investigators did not specifically ask about nausea or other symptoms; rather, those symptoms reported by patients themselves or observed by the investigators were counted.

The same investigators carried out the same assessments on the ward every six hours for $48 \mathrm{hr}$. In addition, at the fourth and eighth visits, overall satisfaction with PCA was graded and recorded on a four-point global satisfaction score: "very good," "good" "fair," and "poor". Meanwhile, data on dosing patterns, demand, delivery and total dose (intraoperative total loading dose was not included) were retrieved from the PCA computer memory at $24 \mathrm{hr}$.

PONV were assessed on a five-point scale every six hours: $0=$ no nausea/vomiting; $\mathrm{l}=$ nausea for less than ten minutes and/or vomiting only once, requiring no treatment; 2 = nausea persisting more than ten minutes and/or vomiting twice, and then subsiding not requiring treatment; 3 = nausea persisting more than ten minutes and/or vomiting more than twice, requiring treatment; $4=$ intractable nausea/vomiting not 
TABLE II Frequency of PCA demand and volume of solution delivered

\begin{tabular}{llllll}
\hline & Group & PACU & Day 1 & Day 2 & Total \\
\hline Demand & $\mathrm{T}+\mathrm{M}$ & $3.1 \pm 2.2$ & $12.4 \pm 6.8$ & $7.0 \pm 2.1$ & $22.5 \pm 11.1$ \\
(Numbers) & $\mathrm{T}$ & $4.5 \pm 1.1$ & $14.9 \pm 7.3$ & $8.2 \pm 4.8$ & $28.4 \pm 16.0$ \\
Solution & $\mathrm{T}+\mathrm{M}$ & $3.1 \pm 2.2$ & $8.1 \pm 6.9$ & $7.5 \pm 4.5$ & $18.7 \pm 13.6$ \\
Delivered $(\mathrm{mL})$ & $\mathrm{T}$ & $3.3 \pm 3.1$ & $10.9 \pm 8.3$ & $6.4 \pm 5.9$ & $20.6 \pm 17.3$ \\
\hline
\end{tabular}

$\mathrm{PCA}=$ patient-controlled analgesia; PACU $=$ postanesthesia care unit. Values are mean \pm SD. No statistical difference between groups.

TABLE III Overall satisfaction

\begin{tabular}{lllllll}
\hline \multirow{2}{*}{ Time } & & \multicolumn{2}{c}{ Satisfaction rate } & $n(\%)$ & Poor & Total \\
\hline PACU & Drugs & Verygood & Good & Fair & $0(0 \%)$ & 20 \\
& $\mathrm{~T}+\mathrm{M}$ & $14(70 \%)$ & $6(30 \%)$ & $0(0 \%)$ & $0(0 \%)$ & 20 \\
Postoperative & $\mathrm{T}$ & $14(70 \%)$ & $4(20 \%)$ & $2(10 \%)$ & $0(0 \%)$ & 20 \\
day 1 & $\mathrm{T}+\mathrm{M}$ & $15(75 \%)^{*}$ & $5(25 \%)$ & $0(0 \%)$ & $0(0 \%)$ & 20 \\
Postoperative & $\mathrm{T}$ & $8(40 \%)$ & $9(45 \%)$ & $3(15 \%)$ & $0(0 \%)$ & 20 \\
day 2 & $\mathrm{T}+\mathrm{M}$ & $17(85 \%)$ & $3(15 \%)$ & $0(0 \%)$ & $0(0 \%)$ & 20 \\
\hline
\end{tabular}

PACU $=$ postanesthesia care unit; $n=$ number of patients. ${ }^{*} \mathrm{P}<0.05$ Group $\mathrm{T}+\mathrm{M} v s \mathrm{~T}$.

TABLE IV Incidence of adverse effects observed in the PACU and at 24 and $48 \mathrm{hr}$ postoperatively

\begin{tabular}{llcllll}
\hline & \multicolumn{3}{c}{$T+M, n(\%), n=20$} & \multicolumn{2}{c}{$T n(\%) n=20$} \\
& $P A C U$ & $24 \mathrm{hr}$ & $48 \mathrm{hr}$ & $P A C U$ & $24 \mathrm{hr}$ & $48 \mathrm{hr}$ \\
\hline nausea & $1(5)$ & $1(5)$ & $0(0)$ & $3(15)$ & $7(35)^{*}$ & $1(5)$ \\
vomiting & $0(0)$ & $0(0)$ & $0(0)$ & $0(0)$ & $5(25)^{*}$ & $1(5)$ \\
shivering & $0(0)$ & $0(0)$ & $0(0)$ & $0(0)$ & $0(0)$ & $0(0)$ \\
dizziness & $0(0)$ & $0(0)$ & $0(0)$ & $0(0)$ & $1(5)$ & $0(0)$ \\
sedation & $9(45)$ & $7(35)^{*}$ & $3(15)$ & $6(30)$ & $1(5)$ & $0(0)$ \\
somnolence & $0(0)$ & $0(0)$ & $0(0)$ & $0(0)$ & $0(0)$ & $0(0)$ \\
dry mouth & $1(18)$ & $0(0)$ & $0(0)$ & $1(5)$ & $2(10)$ & $0(0)$ \\
\hline
\end{tabular}

$n=$ number of patients; PACU = postanesthesia care unit; sedation = patient drowsy or eyes closed but can be aroused using only a verbal command; somnolence $=$ patient arousable only by strong physical stimulation or non-arousable sleep. ${ }^{*} P<0.05 \mathrm{Group} \mathrm{T}+\mathrm{M} v s \mathrm{~T}$.

responding to treatment. For patients with a PONV score of 3 or more, ondansetron $4 \mathrm{mg}$ iv was administered or the PCA was interrupted temporarily.

The incidence of adverse effects such as shivering, dizziness, sedation, somnolence, or dry mouth was assessed and recorded daily. Urinary retention could not be assessed due to the use of indwelling catheters in all patients. When adverse effects were intolerable, the PCA was interrupted temporarily. Sedation was defined as: patient drowsy, or eyes closed but could be aroused using only a verbal command. Somnolence was defined as sleep arousable only by strong physical stimulation or not arousable at all. Respiratory depression was defined as bradypneic episodes lasting more than ten minutes. Respiratory depression or unarousable sleep were to be assessed and reported by any health care personnel and to be treated with oxygenation and re-intubation. Convulsions, if present, were to be treated with $i v$ diazepam $2.5 \mathrm{mg}$ prn.
Our previous study ${ }^{12}$ indicated an incidence of nausea of $48 \%$ in patients receiving PCA with tramadol alone. We estimated an incidence of nausea of less than $15 \%$ in patients receiving PCA with tramadol plus metoclopramide. Power analysis at 0.05 error level with more than $80 \%$ confidence indicated 20 patients in each group were required to detect inter-group difference. The same sample size is applicable for the detection of inter-group difference in sedation if a similar difference is expected.

Data for age, body weight, height, duration of surgery or anesthesia, and tramadol demand or consumption were analyzed with Student- $t$ test and reported as mean $\pm S D$. VAS was analyzed with Mann Whitney U test. Chi-square test was used for sex, physical status, types of surgery, and satisfaction score. Chi-square test and Fisher exact test were used for the analysis of adverse events. A $P$ value $<0.05$ was considered statistically significant. 


\section{Results}

There were no differences between the two groups in terms of demographic data, or type and duration of surgery (Table I).

The intraoperative loading dose of tramadol was similar between the two groups $(147.5 \pm 30 \mathrm{mg}$ in Group $\mathrm{T}+\mathrm{M}$ vs $142.5 \pm 40 \mathrm{mg}$ in Group $\mathrm{T}$ ). The average time from arrival in the PACU to the time when the patient complained of pain (VAS $=6.2 \pm 1.2$ in Group $\mathrm{T}+\mathrm{M}$ vs VAS $=5.6 \pm 1.8$ in Group $\mathrm{T}$ ) requiring analgesia was similar $(15 \pm 12 \mathrm{~min}$ in Group $\mathrm{T}+\mathrm{M}$ os $19 \pm 12 \mathrm{~min}$ in Group $\mathrm{T})$. The onset time of either $\mathrm{T}+\mathrm{M}$ or $\mathrm{T}$ was within four minutes. The mean PACU dose of tramadol was similar $(62 \pm 44 \mathrm{mg}$ for Group $\mathrm{T}+\mathrm{M}$ vs $66 \pm 62 \mathrm{mg}$ for Group T; Table II). After titration with additional doses, all patients achieved a satisfactory analgesia in the PACU.

On the ward, postoperative analgesia was effective at rest throughout the first $48 \mathrm{hr}$. Overall pain relief at each assessment by VAS (mean \pm SD) was comparable between groups and is expressed in Figure 1.

The frequency of PCA demand and tramadol consumption in each group is summarized in Table II. There was no statistical difference between the groups in the number of demands and millilitres of delivery in the PACU, first or second postoperative day. Total tramadol consumption, including the intraoperative loading dose was similar $(521 \pm 302 \mathrm{mg}$ in Group $\mathrm{T}+\mathrm{M}$ and $554 \pm 386 \mathrm{mg}$ in Group $\mathrm{T})$.

Global satisfaction scores in the PACU and on the first and second postoperative days are summarized in Table III. "Very good" satisfaction scores were more frequent in Group $\mathrm{T}+\mathrm{M}$ than in Group $\mathrm{T}$ on the first postoperative day. Otherwise there was no statistical difference between the two groups.

More severe nausea/vomiting was observed from 12 $\mathrm{hr}$ to $24 \mathrm{hr}$ postoperatively in Group $\mathrm{T}$ than in Group $\mathrm{T}+\mathrm{M}(1.7 \pm 1.0$ vs $0.2 \pm 0.5,2.3 \pm 1.2$ vs $0.6 \pm 0.6,1.9$ \pm 0.9 vs $0.2 \pm 0.5$, at $12 \mathrm{hr}, 18 \mathrm{~h}, 24 \mathrm{hr}$, respectively, $P<$ 0.05 , Figure 2). The incidence of nausea/vomiting was also higher in Group $\mathrm{T}$ than in Group $\mathrm{T}+\mathrm{M}$ the first postoperative day $(7 / 20$ or $35 \%$ vs $1 / 20$ or $5 \%, 5 / 20$ or $25 \%$ vs $0 \%$ for nausea and vomiting respectively, $P<0.05$, Table IV). Two patients in Group $\mathrm{T}$ required iv ondansetron treatment. The severity and incidence of nausea/vomiting were similar in the PACU and on the second postoperative day in both groups. The incidence of sedation was higher in Group $\mathrm{T}+\mathrm{M}$ than in Group $\mathrm{T}$ on the first postoperative day $(7 / 20$ or $35 \%$ vs $1 / 20$ or $5 \%, P<0.05$, Table IV). There was no statistical difference between the two groups in terms of other side effects such as shivering, sedation, dizziness, pruritus, dry mouth, etc., in the PACU and during the 48-hr observation period. None of the patients had a seizure, a

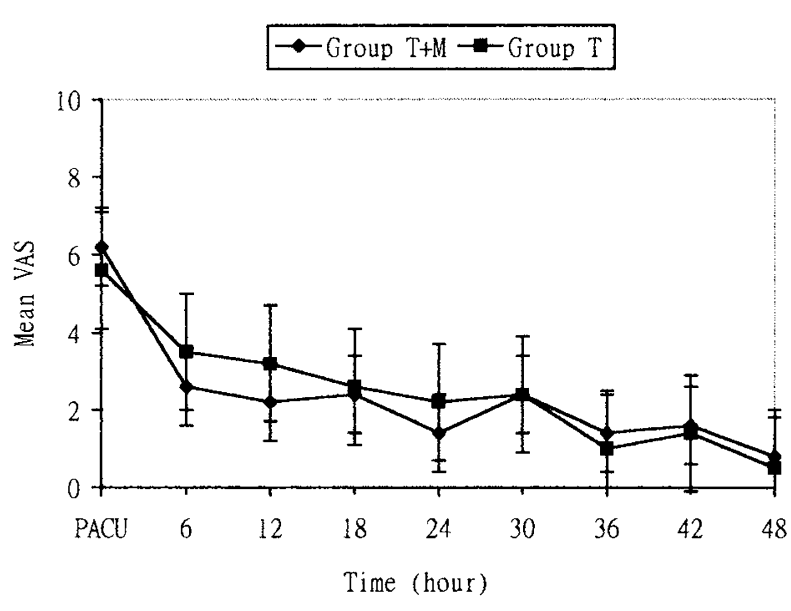

FIGURE 1 Overall pain relief by visual analogue scale (VAS) assessment in the postoperative period. PACU $=$ postanesthesia care unit. No statistical difference between groups.

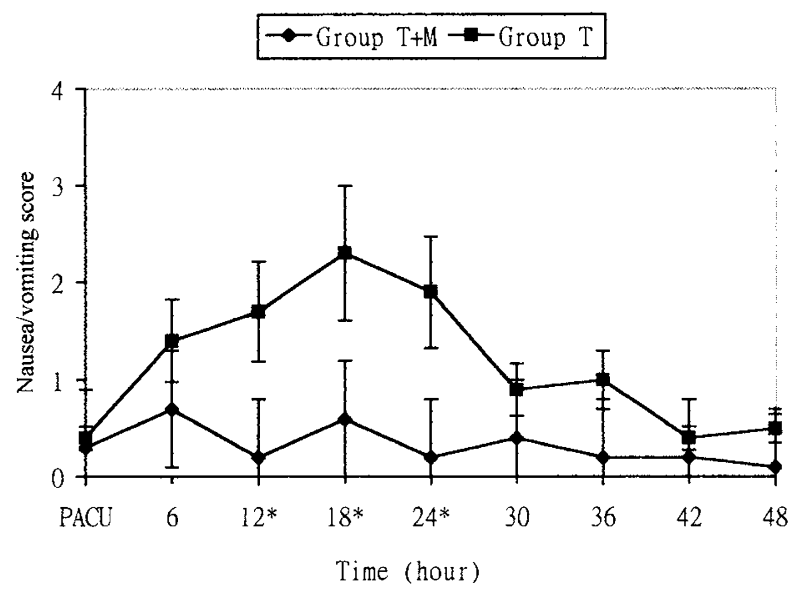

FIGURE 2 Nausea/vomiting scores (mean \pm standard deviation). $\mathrm{PACU}=$ postanesthesia care unit. ${ }^{*} \mathrm{P}<0.05$ Group $\mathrm{T}+\mathrm{M} v s \mathrm{~T}$.

sedation score of 4 (unarousable sleep) or respiratory depression. None of the adverse effects warranted terminating PCA use and vital signs were stable in all patients.

\section{Discussion}

This study showed that tramadol PCA provides effective analgesia following major orthopedic surgery. The incidence of nausea/vomiting associated with tramadol is reduced and the satisfaction rate is increased if metoclopramide is added to tramadol for PCA. However, more sedation is observed in patients receiving $\mathrm{T}+\mathrm{M}$. 
Administration of the loading dose under general anesthesia probably explains the low incidence of nausea observed in both groups. Our previous study showed that if a loading dose of tramadol PCA is given in the PACU to achieve analgesia, almost half of the patients will complain of nausea. ${ }^{12}$ Nausea/vomiting appears to be dose and administration rate related and can be reduced by loading the drug before the end of surgery. ${ }^{13}$ We have shown that adding metoclopramide to tramadol PCA will further decrease nausea/vomiting.

Metoclopramide, initially marketed as an antiemetic drug during pregnancy, was subsequently found to have multiple pharmacological effects, e.g., prokinetic, ${ }^{6}$ antispasmodic, ${ }^{7}$ and, more recently, analgesic with various proposed mechanisms. ${ }^{5-8}$ With the use of anti-emetic doses, we did not find that tramadol consumption was reduced in Group $\mathrm{T}+\mathrm{M}$ although the anti-emetic effect was clear.

Interestingly, sedation was more frequent in patients who received the tramadol with metoclopramide. In the anti-emetic dose range, metoclopramide does not possess sedative effect. However, sedative effect can potentiated by the interaction with alcohol, hypnotics, tranquilizers, or narcotics. ${ }^{11}$

The more frequent "very good" satisfaction score in Group $\mathrm{T}+\mathrm{M}$ on the first postoperative day was possibly related to reduced nausea/vomiting. In the study by Furuya et al., when patients were assessed postoperatively, the most undesirable perioperative outcome was nausea/vomiting which can be improved by preoperative explanation and preventive management. ${ }^{14}$

In summary, tramadol PCA provides effective analgesia following major orthopedic surgery. PCA with tramadol and metoclopramide is associated with a decreased incidence and severity of nausea/vomiting compared to PCA with tramadol alone. Patient satisfaction is increased despite the increased incidence of sedation observed with this combination.

\section{Acknowledgements}

The authors thank Chiu-Kuei Niang, MSc. for statistic advice, chief CRNA Shu-Hui Young, and the team members who corroborated this work.

\section{References}

1 Raffa RB, Nayak RK, Liao S, Minn FL. The mechanism(s) of action and pharmacokinetics of tramadol hydrochloride. Rev Contemp Pharmacother 1995; 6: 485-97.

2 Scott LJ, Perry CM. Tramadol: a review of its use in perioperative pain. Drugs 2000; 60: 139-76.

3 Vickers MD, O'Flaberty D, Szekely SM, Read M, Oshizumi J. Tramadol: pain relief by an opioid without depression of respiration. Anaesthesia 1992; 47: 291-6.

4 Scott LJ, Perry CM. Tramadol, a review of its use in perioperative pain. Drugs 2000; 1: 139-76.

5 Kandler D, Lisander B. Analgesic action of metoclopramide in prosthetic hip surgery. Acta Anaesthesiol Scand 1993; 37: 49-53.

6 Rosenblatt WH, Cioffi AM, Sinatra R, Saberski LR, Silverman DG. Metoclopramide: an analgesic adjunct to patient-controlled analgesia. Anesth Analg 1991; 73: 553-5.

7 Hedenbro JL, Olsson AM. Metoclopramide and ureteric colic. Acta Chir Scand 1988; 154: 439-40.

8 Lisander B. Evaluation of the analgesic effect of metoclopramide after opioid-free analgesia. Br J Anaesth 1993; 70: 631-3.

9 Katz WA. Pharmacology and clinical experience with tramadol in osteoarthritis. Drugs 1996; 52(Suppl 3): 39-47.

10 Reisine T, Pasternak G. Opioid analgesics and antagonists. In: Hardman JG, Limbird LE, (Eds.). The pharmacological Basis of Therapeutics, $9^{\text {th }}$ ed. McGraw-Hill, International Edition, 1996: 933.

11 Omoigui S. The Pain Drugs Handbook. St Louis, Missouri: Mosby-Year Book Inc., 1995: 287.

12 Pang WW, Mok MS, Lin CH, Yang TF, Huang MH. Comparison of patient-controlled analgesia (PCA) with tramadol or morphine. Can J Anesth 1999; 46: 1030-5.

13 Pang WW, Mok MS, Huang S, Hung CP, Huang MH. Intraoperative loading attenuates nausea and vomiting of tramadol patient-controlled analgesia. Can J Anesth 2000; 47: 968-73.

14 Furuya $H$, Nakahashi K, Hirai $K$, et al. Assessment of anesthesia satisfaction using direct interviews at postanesthesia clinic (Japanese). Masui 2001; 50: 240-5. 